\title{
Spinal or Intravenous Dexmedetomidine for Spinal Anesthesia with Chloroprocaine in Ambulatory Knee Arthroscopies: A Double-Blind Randomized Trial
}

\author{
Margaretha B Breebaart $\mathbb{D}^{1,2}$ \\ Lies Saerens ${ }^{3}$ \\ Jordi Branders ${ }^{2}$ \\ Sari Casaer ${ }^{3}$ \\ Luc Sermeus ${ }^{4}$ \\ Patrick Van Houwe ${ }^{3}$ \\ 'Department of Medicine and Healthcare \\ Sciences, University of Antwerp, Wilrijk, \\ Belgium; ${ }^{2}$ Department of Anesthesia, \\ Antwerp University Hospital, Edegem, \\ Belgium; ${ }^{3}$ Department of Anesthesia, \\ GZA Hospitals, Wilrijk, Belgium; \\ ${ }^{4}$ Department of Anesthesia, Université \\ Catholique de Louvain, Brussel, Belgium
}

Correspondence: Margaretha B Breebaart Email margaretha.breebaart@uza.be
Purpose: Chloroprocaine provides spinal anesthesia for day-case surgery lasting up to 40 minutes. Intravenous and spinal dexmedetomidine can prolong spinal anesthesia, but no data are available for the combination with chloroprocaine. This double-blind randomized controlled trial compares chloroprocaine with spinal or intravenous dexmedetomidine regarding block characteristics, micturition, and discharge times.

Patients and Methods: After ethical approval and informed consent, 135 patients scheduled for knee arthroscopy were randomized to receive either 40mg spinal chloroprocaine (Chloro-group), 40mg chloroprocaine with $5 \mathrm{mcg}$ spinal dexmedetomidine (Spinal Dexgroup) or $40 \mathrm{mg}$ chloroprocaine with $0.5 \mathrm{mcg} / \mathrm{kg}$ IV dexmedetomidine (IV DEXgroup). Block characteristics, hemodynamic variables and the use of analgesics were registered. Voiding and discharge times were noted. A scoring system was used for micturition problems and sedation. Transient neurological symptoms (TNS) and other late side effects were evaluated after one week.

Results: Demographic data were similar between groups. Block onset times and intensity of motor block were comparable between groups. The time to L2 and Bromage 1 regression was prolonged in the SpinalDEx-group by approximately 30 minutes compared to the other groups $(\mathrm{p}<0.01)$. First voiding as well as discharge from the hospital was prolonged in the Spinal Dex-group by approximately 40 minutes $\mathrm{p}<0.01$. There was no significant difference between groups regarding treatment of hypotension, sedation, micturition problems or the use of postoperative analgesics $(\mathrm{P}>0.8)$. One patient experienced TNS.

Conclusion: Intrathecal but not intravenous $(0.5 \mathrm{mcg} / \mathrm{kg})$ dexmedetomidine can prolong chloroprocaine (40mg) spinal anesthesia when surgery is expected to last over 40 minutes. Despite a similar incidence of adverse effects, this also led to a postponed hospital discharge time.

Keywords: ambulatory surgery, bladder function, chloroprocaine, dexmedetomidine, knee arthroscopy, spinal anesthesia

\section{Introduction}

The re-introduction of chloroprocaine and its recent approval for spinal use has provided an interesting alternative to lidocaine for spinal anesthesia. ${ }^{1}$ In a recent study, we showed that $40 \mathrm{mg}$ of chloroprocaine results in short-lasting sensory blocks, allows early discharge and has a low incidence of micturition problems, even when administering an extra IV fluid load. ${ }^{2}$ The spinal use of chloroprocaine is recommended for procedures lasting less than 40 minutes. Therefore, unforeseen prolonged surgery may require conversion to general anesthesia. 
To increase the duration of the spinal sensory block, one can increase the dose, or administer an additive such as clonidine or an opioid. However, these additives may induce side effects such as an increase in micturition problems, pruritus, sedation, bradycardia, respiratory depression, or hypotension. ${ }^{3-5}$

Dexmedetomidine is an $\alpha 2$-adreno receptor agonist that produces dose-dependent sedation, anxiolysis and analgesia without respiratory depression. It prolongs spinal anesthesia, with a low incidence of side effects, when added intrathecally. ${ }^{6}$ Intravenous dexmedetomidine can prolong spinal anesthesia by $34 \%{ }^{7}$

Currently, there are no clinical randomized trials investigating the intravenous or spinal addition of dexmedetomidine to chloroprocaine, or other short-acting local anesthetics, in an ambulatory setting.

The primary objective of this double-blind randomized study was to determine the effect of dexmedetomidine on the onset and duration of the sensory and motor block. Our primary hypothesis was that the L2-regression of the sensory block would be significantly prolonged by dexmedetomidine, both by the spinal and the intravenous routes. Secondary outcomes were the incidence of micturition problems, duration of analgesia and the occurrence of side effects such as sedation and hypotension.

\section{Patients and Methods}

This multicenter trial was performed at the Antwerp University Hospital and GZA Hospital. The trial was approved by the ethical committee of the University Hospital of Antwerp and the ethical committee of Sint Augustinus Hospital (nr B300201319186) in December 2013. The trial was performed in accordance with the declaration of Helsinki and good clinical practice and was registered at clinicaltrials. gov NCT02282319 in November 2014. All patients of ASA class 1 aged 18-70 who were scheduled for ambulatory knee arthroscopy were asked for informed consent.

Exclusion criteria were a contraindication for spinal anesthesia, history of neurological deficit, previous lower abdominal surgery, a body mass index $>35 \mathrm{~kg} / \mathrm{m}^{2}$, history of abnormal micturition and allergy or hypersensitivity to local anesthetics. Patients were assigned to one of the following three study groups by computer-generated randomization:

\section{The Chloro-Group}

$40 \mathrm{mg}$ spinal chloroprocaine 1\% (Ampres ${ }^{\circledR}$, Nordic Pharma, Belgium) with $0.5 \mathrm{~mL}$ spinal $\mathrm{NaCl} 0.9 \%$ (total $4,5 \mathrm{~mL}$ ) and $50 \mathrm{~mL} \mathrm{NaCl} 0.9 \%$ Intravenously (IV).

\section{The Spinal DEX-Group}

$40 \mathrm{mg}$ spinal chloroprocaine 1\% (Ampres ${ }^{\circledR}$, Nordic Pharma, Belgium) with $5 \mathrm{mcg}$ spinal dexmedetomidine (Dexdor ${ }^{\circledR}$, Orion Pharma, Belgium) $(0.5 \mathrm{~mL}$ of $10 \mathrm{mcg} / \mathrm{mL})$ and 50 $\mathrm{mL} \mathrm{NaCl} \mathrm{0.9 \%} \mathrm{IV.}$

\section{The IV DEX-Group}

$40 \mathrm{mg}$ spinal chloroprocaine 1\% (Ampres ${ }^{\circledR}$, Nordic Pharma, Belgium) with $0.5 \mathrm{~mL}$ spinal $\mathrm{NaCl} 0.9 \%$ (total $4,5 \mathrm{~mL}$ ) and $0.5 \mathrm{mcg} / \mathrm{kg}$ dexmedetomidine (Dexdor ${ }^{\circledR}$, Orion Pharma, Belgium) in $50 \mathrm{~mL} \mathrm{NaCl} \mathrm{0.9 \%} \mathrm{IV.}$

The anesthetist performing the spinal anesthesia, the patient and the observer were blinded for the assigned study-group. An independent anesthesiologist prepared the study medication in identical appearing syringes.

No premedication was prescribed. Patients were asked to void 15 minutes prior to transfer to the operating room. Post voiding residual volume (PVRV) was measured by bladder scanning. If PVRV was above $100 \mathrm{~mL}$, patients were excluded from the study. A 20 Gauge IV cannula was placed and IV (Plasmalyte or $\mathrm{NaCl} 0.9 \%$ ) was started at $2 \mathrm{~mL} / \mathrm{kg} / \mathrm{hr}$.

Spinal anesthesia was performed in the sitting position with a $27 \mathrm{G}$ Whitacre needle $\left(\mathrm{BD}^{\circledR}\right.$, Madrid, Spain) at the L3-L4 vertebral interspace. The local anesthetic was injected slowly with the bevel oriented to the operative side. Directly after injection, the patient was turned supine and the IV study medication (dexmedetomidine or $\mathrm{NaCl}$ $0.9 \%$ ) was administered over 5 minutes.

After spinal injection, the evolution of the spinal block was registered by loss of cold sensation and registration of the Bromage score $(0=$ no block, $1=$ flexion knee, $2=$ movement toes $3=$ total block) every 5 minutes for the first 30 minutes and every 10 minutes until L2 regression. Sedation was scored every 15 minutes with a 6-point

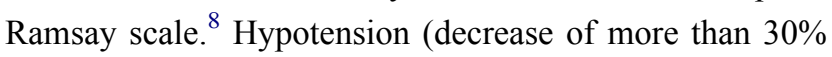
of baseline) was treated with ephedrine and bradycardia $(<45$ BPM $)$ with atropine. Patients requiring supplementary analgesia received sufentanil IV. If the required sufentanil dose exceeded $0.15 \mathrm{mcg} / \mathrm{kg}$, general anesthesia was induced. The duration of surgery was registered.

After surgery, patients were transferred to the post anesthesia care unit (PACU). The measurement of vital parameters and sedation was continued every 15 minutes. Bladder scanning was performed on arrival $\left(\mathrm{DXU}^{\circledR}\right.$, Verathon, Ijsselstein, The Netherlands). ${ }^{9}$ If bladder volume was less than $150 \mathrm{~mL}$, the IV fluid regimen was increased to $6 \mathrm{~mL} / \mathrm{kg}$ for 1 hour. Patients were discharged from the 
PACU when motor block had recovered (Bromage score $1)$, the hemodynamic parameters were stable, and the painscore was $<4$ on the Numeric Rating Scale (NRS). Block characteristics were registered in the PACU and the Day Case Unit (DCU) every 15 minutes until complete block regression.

In the DCU, bladder volumes were monitored hourly as well as before and after micturition. All arrival and departure times between the different departments were registered. Patients were asked to void when bladder volume reached $400 \mathrm{~mL}$. A single "in/out" bladder catheterization was performed when bladder volume exceeded $500 \mathrm{~mL}$ or PVRV exceeded $300 \mathrm{~mL}$ if the patient was unable to void spontaneously within 15 minutes.

In the DCU, pain was treated with paracetamol $(1000 \mathrm{mg})$ and ketorolac $(0.5 \mathrm{mg} / \mathrm{kg})$ when the NRS was $>3$. IV rescue analgesia was provided with tramadol $(2 \mathrm{mg} / \mathrm{kg})$.

Hospital discharge criteria were ability to ambulate, NRS score $<3$, no PONV and a PVRV of less than $100 \mathrm{~mL}$. We used a modified micturition score from two previous trials ${ }^{2,10}$ based on bladder volumes, PVRV and subjective complaints during micturition such as use of abdominal strain, pain or feeling of incomplete voiding (Table 1).

One week later, patients were contacted to determine the presence of the following postoperative symptoms:

Table I Classification of Micturition Problems

\begin{tabular}{|c|c|}
\hline 0 & No problems \\
\hline I & $\begin{array}{l}\text { Minor micturition problems } \\
\text { A) Subjective difficulties* or feeling of incomplete voiding or } \\
\text { PVRV** } 50-100 \mathrm{~mL} \\
\text { B) Bladder volume }>500 \mathrm{~mL} \text {, no urge but voids }<15 \mathrm{~min} \text { and } \\
\text { PVRV }<100 \mathrm{~mL} \text { (no difficulty) }\end{array}$ \\
\hline 2 & $\begin{array}{l}\text { Moderate micturition problems: } \\
\text { Combination of } 2 \text { or more Class IA problems and PVRV } \\
<100 \mathrm{~mL} \\
\text { PVRV }>300 \mathrm{~mL} \text { but voids within } 15 \text { minutes with PVRV }<100 \\
\mathrm{~mL} \text { (even if difficulty) }\end{array}$ \\
\hline 3 & $\begin{array}{l}\text { Marked micturition problems: } \\
\text { Significant difficulties with PVRV } 100-300 \mathrm{~mL}\end{array}$ \\
\hline 4 & $\begin{array}{l}\text { Serious micturition problems } \\
\text { Single in and out evacuation }\end{array}$ \\
\hline
\end{tabular}

Notes: **Subjective difficulties: abdominal pain or strain during voiding. *PVRV, post voiding residual volume. Reprinted from $\mathrm{Br} J$ Anaesth,90, Breebaart MB, Vercauteren MP, Hoffmann VL, et al. Urinary bladder scanning after day-case arthroscopy under spinal anaesthesia: comparisonbetween lidocaine, ropivacaine, and levobupivacaine, 309-313, Copyright 2003, with permission from Elsevier. ${ }^{10}$ back pain, symptoms of TNS, headache, micturition problems or other complaints.

\section{Statistical Analysis}

Sample size was calculated based on the previously published L2 regression time for chloroprocaine. ${ }^{2}$ Assuming a regression time of $90 \pm 30 \mathrm{~min}$ (mean $\pm \mathrm{SD}$ ) we calculated that 35 patients were required per group, to detect a $30 \%$ difference ( $27 \mathrm{~min}$ ) between groups (independent samples $t$-test, $90 \%$ power and a corrected alpha error of $5 \%$ ).

To account for possible dropouts, we chose a sample size of 45 patients for each group. Statistical tests were performed with SPSS IBM, version 26. Normality of the data was tested by the Kolmogorov-Smirnov test. Normally distributed data are presented as mean (SD) and were compared by analysis of variance. Non normally distributed data were compared using the Mann Whitney $U$-test. Binomial data were compared with the Pearson Chi-square test. A p value of $<0.05$ was considered statistically significant.

\section{Results}

Patients were included from November 2014 to March 2020. Of all patients assessed for eligibility (709), 141 were included after giving informed consent ( 92 male, 49 female). Of these, 5 patients were excluded due to technical difficulties or a vasovagal reaction during spinal puncture. In one patient, the protocol was violated (Figure 1).

There were no differences in demographics or surgical operating time between groups (Table 2). Two patients in de Chloro-group and two patients in de IV DEX-group received general anesthesia because of insufficient block during surgery. Block onset and quality characteristics are shown in Table 3. There was no difference in onset time for the maximum motor or sensory block between groups. The mean onset time for the sensory block to reach the T12 dermatome was 8 minutes in all groups. Maximum sensory spread is displayed in Figure 2. In the IV DEX-group 11 patients had a sensory a block below the T12-dermatome. This was significantly greater than in the Chloro and Spinal DEX-groups, where the block was below the T12 dermatome only in 2 and 4 patients, respectively. Of these 11 patients in the IV DEX group, 7 patients had a full motor block (Bromage 3). Supplemental sufentanil was administered to 3 patients in the Chloro-group, none in the Spinal DEX-group and 1 patient in the IV DEX-group. Maximum Bromage score was comparable between groups. Baseline blood pressure, as well as the lowest systolic and diastolic 


\section{CONSORT 2010 Flow Diagram}

\section{Enrollment}

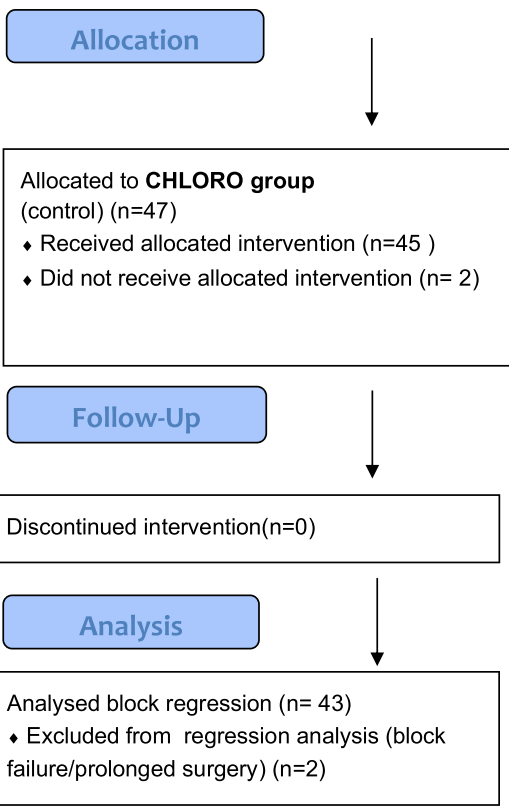

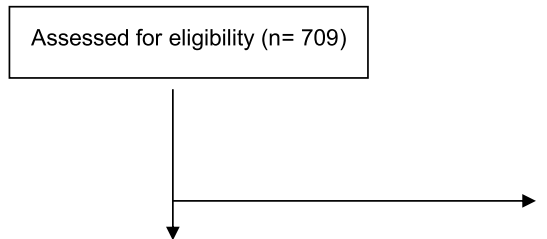

Excluded $(n=568)$ Patient refusal $(n=76)$

Prefer general anaesthesia $(n=328)$

$\mathrm{Cl}$ spinal anesthesia( $n=42)$

Neurological deficit $(n=35)$

Micturition problems $(n=33)$

Other reasons $(n=54)$
Other

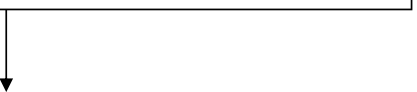

Allocated to SpinalDEX group

Spinal dexmedetomidine $(n=47)$

- Received allocated intervention $(n=45)$

- Did not receive allocated intervention (spinal could not be performed/protocol violation) $(n=2)$

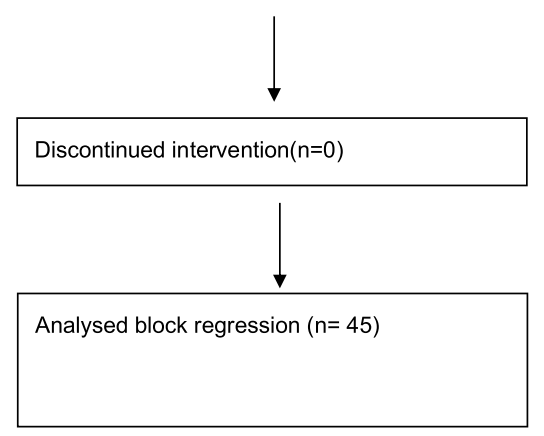

Allocated to IVDEX group

Intravenous dexmedetomidine $(n=47)$

- Received allocated intervention $(n=45)$

- Did not receive allocated intervention (give reasons) $(n=2)$

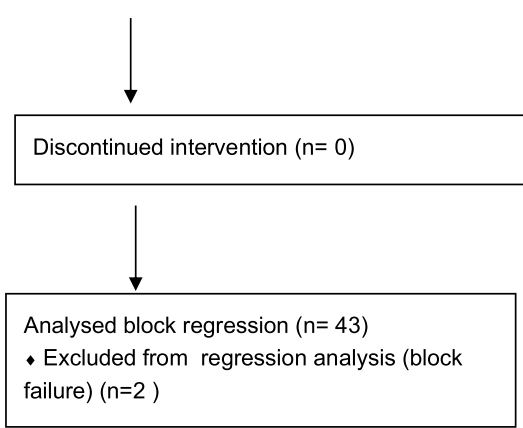

Figure I Consort flowchart.

blood pressures, did not differ between groups. Ephedrine was administered to seven patients in the Spinal DEXgroup and to five patients each in the IV DEX and Chloro-

Table 2 Demographic Data and Time of Surgery

\begin{tabular}{|l|c|c|c|c|}
\hline & $\begin{array}{c}\text { Chloro } \\
\mathbf{( 4 5 )}\end{array}$ & $\begin{array}{c}\text { SpinaIDEX } \\
\mathbf{( 4 5 )}\end{array}$ & $\begin{array}{c}\text { IVDEX } \\
\mathbf{( 4 5 )}\end{array}$ & $\begin{array}{c}\text { p- } \\
\text { value }\end{array}$ \\
\hline Age (years) & $45(15)$ & $51(14)$ & $47(12)$ & 0.2 \\
Length (cm) & $175(11)$ & $175(9)$ & $176(9)$ & 0.9 \\
Weight (kg) & $81(16)$ & $81(11)$ & $81(12)$ & 0.9 \\
Time surgery (min) & $20(17)$ & $22(12)$ & $21(13)$ & 0.7 \\
\hline
\end{tabular}

Note: Data are presented as mean (standard deviation). groups. Three patients in the Chloro-group and three patients in the IV DEX-group received atropine.

Motor and sensory block regression and discharge times are shown in Table 4. Both the time for sensory block regression to the $\mathrm{L} 2$ dermatome and full recovery of motor function (Bromage 0) were significantly prolonged in the Spinal DEX-group compared to the other groups. First ambulation and discharge from the DCU were also delayed by approximately 30 minutes for the Spinal DEXgroup compared to the other groups. There were no differences in block regression or discharge times between the

Table 3 Onset and Block Quality

\begin{tabular}{|l|c|c|c|}
\hline & Chloro (45) & SpinalDEX (45) & IVDEX (45) \\
\hline T max sensory block dermatome (min) & $20(3-43)$ & $19(6-74)$ & $21(3-95)$ \\
Mean onset TI2 (min) & $8(6)$ & $8(6)$ & $8(5)$ \\
Max Bromage score 0/I/2/3 (number of patients) & $2 / 1 / 4 / 38$ & 0.3 & $2 / 2 / 5 / 36$ \\
Block below TI2 (number of patients) & $5 / 45$ & $2 / 45$ & $1 / / 45 *$ \\
Opioid supplement & $3+2\left(G A^{*}\right)$ & 0 & $1+2\left(G A^{*}\right)$ \\
(number of patients) & & 0.01 & P $>0.8$ \\
\hline
\end{tabular}

Notes: Data are presented as mean (standard deviation) or median (range) or amount. (number of patients) *GA, general anesthesia. 


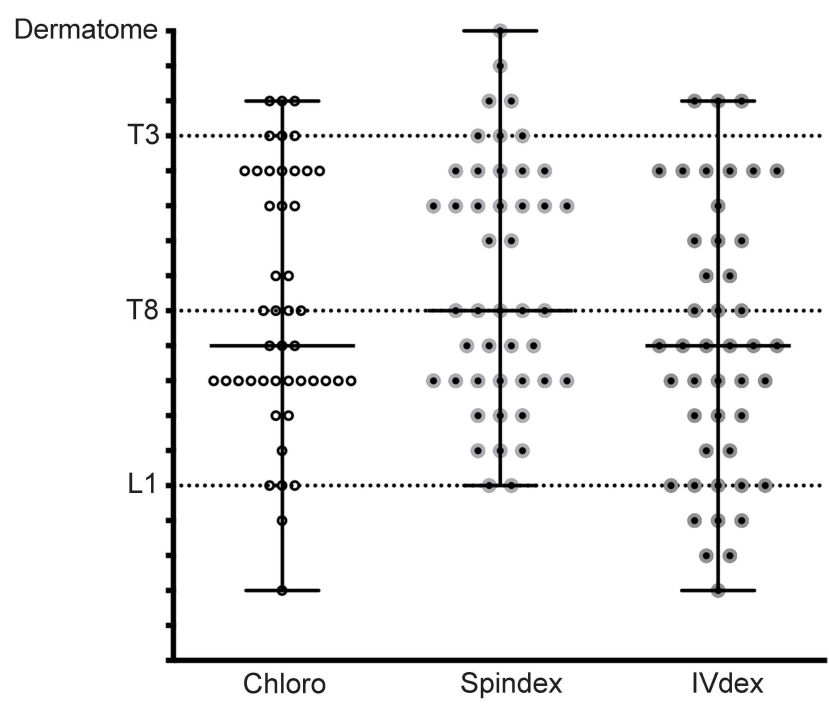

Figure 2 Maximum sensory spread, tested by cold sensation.

Chloro and the IV DEX-group. The median Ramsay scores were comparable between groups and varied between 1 and 3 in all groups.

The number of patients requesting analgesia before termination of the study was as follows: Chloro-group: 15 (33\%), Spinal DEX-group: 13 (29\%), IV DEXgroup:13 (29\%) ( $p>0.8)$. Time to first analgesic request was not statistically different between groups: Chloro-group, 40 \pm 71 minutes, Spinal DEX-group 52 \pm 87 minutes and IV DEX group $51 \pm 71$ minutes ( $p$ $>0.8)$.

Bladder volumes, voiding times, mean IV fluid and micturition problems are summarized in Table 5. The mean time for first voiding was approximately 40 minutes longer for the patients in the Spinal DEX-compared to the other two groups. Four patients had to be catheterized, two in the IV DEX and two in the Spinal DEX-group. There were no differences in bladder volumes, micturition problems or mean administered IV fluid volume between the three groups.
After discharge, six patients could not be reached by telephone for the one week follow-up. Sixteen patients complained of slight back pain: Chloro-group, 3 (6\%), Spinal DEX-group, 9 (20\%), IV DEX-group, 4 (9\%) (p > 0.1). Thirteen patients $(10 \%)$ experienced headache. One patient in the Chloro-group complained of unilateral pain in the back radiating to the knee, combined with severe postoperative pain (NRS 9/10) for which the knee was infiltrated with Marcaine in an ambulatory setting one day after surgery.

\section{Discussion}

Chloroprocaine has been reintroduced in several countries for some years now as a good local anesthetic with an ultrashort duration of action of 40 minutes for spinal anesthesia. To our knowledge, there are no trials investigating the addition of dexmedetomidine to spinal anesthesia with chloroprocaine, either by the spinal or intravenous route. Our results demonstrate that $5 \mathrm{mcg}$ spinal dexmedetomidine prolongs the sensory and motor block of 40 $\mathrm{mg}$ chloroprocaine without influencing onset or block height when compared with control. Intravenous dexmedetomidine in a dose of $0.5 \mathrm{mcg} / \mathrm{kg}$ did not prolong the sensory or motor block.

When $5 \mathrm{mcg}$ dexmedetomidine is added to hyperbaric or plain bupivacaine, motor and sensory block are prolonged compared to bupivacaine alone or bupivacaine with midazolam, buprenorphine, or fentanyl. ${ }^{11-13}$ According to our findings, as in most of these trials, the onset time of the sensory and motor block was comparable for both local anesthetic alone and local anesthetic with dexmedetomidine. However, when different doses of spinal dexmedetomidine were compared, a dosedependent decrease of onset time for sensory and motor block was observed. ${ }^{6,14}$

Naaz et al recorded a $50 \%$ increase in the two segment regression time of sensory block after adding 5 mcg spinal dexmedetomidine when compared to the same dose

Table 4 Regression, Voiding and Discharge Times

\begin{tabular}{|l|c|c|c|c|}
\hline & Chloro (43) & SpinalDEX (45) & IVDEX (43) & P-value \\
\hline T bromage I (min) & $68(19)$ & $104(32)^{*}$ & $74(18)$ & $<0.00 \mathrm{I}$ \\
T motor block (min) & $83(28)$ & $128(35)^{*}$ & $90(26)$ & $<0.00 \mathrm{I}$ \\
T L2 regression (min) & $78(22)$ & $115(39)^{*}$ & $84(27)$ & $<0.00 \mathrm{I}$ \\
T PACU**discharge (min) & $89(24)$ & $116(31)^{*}$ & $93(23)$ & $<0.00 \mathrm{I}$ \\
T ambulation (min) & $173(39)$ & $213^{*}(49)$ & $187(44)$ & $<0.0 \mathrm{I}$ \\
T discharge (min) & $195(46)$ & $236 *(57)$ & $200(43)$ & $<0.01$ \\
\hline
\end{tabular}

Notes: Data are presented as mean (standard deviation). *Significantly different from the IVdex and the chloro-group. **PACU, post anesthesia care unit. 
Table 5 Micturition Characteristics and IV Fluid

\begin{tabular}{|c|c|c|c|c|}
\hline & Chloro (43) & SpinalDEX (45) & IVDEX (43) & p-value \\
\hline $\mathrm{T}$ micturition (min) & $168(40)$ & $211 *(50)$ & $182(48)$ & $<0.01$ \\
\hline Micturition problems class Number of patients (\%) & & & & 0.1 \\
\hline 0 & $29(67 \%)$ & $18(40 \%)$ & $29(67 \%)$ & \\
\hline I & II (26\%) & $16(36 \%)$ & $9(21 \%)$ & \\
\hline 2 & $\mathrm{I}(2 \%)$ & I (2\%) & I (2\%) & \\
\hline 3 & $2(5 \%)$ & $8(18 \%)$ & $2(5 \%)$ & \\
\hline 4 & $0(0 \%)$ & $2(4 \%)$ & $2(5 \%)$ & \\
\hline Mean Volume before voiding $(\mathrm{mL})$ & $419(153)$ & $422(198)$ & $352(152)$ & 0.1 \\
\hline Mean IV fluid $(\mathrm{mL})$ & $816(269)$ & $897(302)$ & 849 (289) & $p>0,3$ \\
\hline
\end{tabular}

Notes: Data are presented as mean (standard deviation) or amount of patients *p $<0.05$.

hyperbaric bupivacaine without additives. ${ }^{6}$ This concurs with the $45 \%$ increase in L2-regression time in our trial. Motor block was also prolonged in two trials adding $5 \mathrm{mcg}$ of dexmedetomidine to bupivacaine. ${ }^{12}$

The prolongation of spinal sensory block by dexmedetomidine with chloroprocaine is not surprising. Dexmedetomidine has been consistently shown to prolong both sensory and motor block when combined with spinal bupivacaine, prilocaine and ropivacaine. Furthermore, Davis et al found an increase in sensory and motor block duration on adding $15 \mathrm{mcg}$ of the alpha- 2 agonist clonidine, to $30 \mathrm{mg}$ spinal chloroprocaine in a small volunteer cross over trial. $^{15}$

The mechanism by which alpha- 2 agonists prolong the motor and sensory block of local anesthetics is not completely understood. Binding the alpha-2 adrenergic receptor could directly inhibit the release of pro-nociceptive transmitters like substance $\mathrm{P}$ and glutamate. ${ }^{16,17}$

A meta-analysis with 364 patients indicated that IV dexmedetomidine can prolong motor and sensory block by at least $34 \%$. The hypothesized mechanism is a central effect on the descending spinal noradrenergic pathway which results in analgesia by terminating pain signal propagation. $^{7}$

Controversially, in our trial, this finding could not be reproduced. Administration of IV dexmedetomidine did not prolong sensory or motor block after spinal anesthesia with $40 \mathrm{mg}$ of chloroprocaine.

We do not have a clear explanation for the fact that in our trial no effect of IV dexmedetomidine was seen on the duration of the block. The dose we used could have been too small or given too late. It has been shown that delaying administration of IV dexmedetomidine by 30 minutes after spinal injection of bupivacaine produced no effect. ${ }^{18}$ However, even lower doses such as $0.25 \mathrm{mcg} / \mathrm{kg}$ IV dexmedetomidine, infused directly after the spinal anesthesia with hyperbaric bupivacaine, did prolong the duration of the sensory block. This suggests that a dosing issue is unlikely to be the explanation for the lack of effect on block duration in our study. ${ }^{19}$

We observed more "low" sensory blocks in the IV DEX-group than in the other groups. Low sensory blocks are often considered as failed blocks with the assumption that part of the injected solution went epidurally after suboptimal needle placement. ${ }^{20}$ The patients with "low blocks" mostly underwent surgery without the need for extra analgesia. The majority had a full motor block, which indicates there was no block failure. Although more patients in the IV DEX group had low sensory blocks, there was no difference with the Chloro-group as far as motor block, or the number of patients requiring supplementary analgesia with sufentanil or even general anesthesia, was concerned.

In accordance with previous trials using bupivacaine and $0.5 \mathrm{mcg} / \mathrm{kg}$ dexmedetomidine, our study did not result in hemodynamic or neurological side effects in any of the groups. ${ }^{19}$ Naaz et al observed significant hypotension only when doses of more than 15 mcg dexmedetomidine were combined with hyperbaric bupivacaine. ${ }^{21}$

Dexmedetomidine did not cause sedation in our trial. Sedation has been described with $0.5 \mathrm{mcg} / \mathrm{kg}$ during spinal anesthesia with bupivacaine. ${ }^{19,22}$ The mean age of the populations in these trials was higher, however, which might explain a more pronounced effect of the same IV dose.

No differences were seen in micturition scores between groups. The incidence of catheterization was $1.5 \%$ which 
is in agreement with our previous trial. ${ }^{2}$ The prolongation of the sensory block by spinal dexmedetomidine caused a delay in voiding time but without any micturition problems.

The gain of 30 minutes to L2 regression in the spinal DEX-group occurred at the expense of a delay in discharge time of 40 minutes. Nevertheless, a discharge time of 235 minutes compares favorably to the alternatives for chloroprocaine when surgery outlasts 45 minutes. For example, discharge times between 205 and 330 minutes have been described for prilocaine. ${ }^{23}$

Spinal and IV dexmedetomidine can prolong postoperative analgesia after spinal anesthesia. We could not detect a delay to first analgesic request. However, $31 \%$ of our patients did not request any analgesic until the moment of discharge and termination of the trial.

No case of TNS was detected during the postoperative follow-up, although one patient experienced radiating pain. This patient also experienced severe knee pain for which an infiltration was performed. This combination is not typical of TNS, but the diagnosis cannot be ruled out.

Several possible drawbacks to this study might be discussed. We used a single shot low IV dose of dexmedetomidine that might have been too low to cause an effect on the duration of spinal anesthesia. Higher doses are known to cause side effects. Although spinal dexmedetomidine prolongs sensory block and surgical operating time, its use by this route is "off label". FDA-approved local anesthetics, such as prilocaine, provide a similar intermediate duration of action, without additives. In this trial, we anticipated that IV dexmedetomidine would prolong the sensory block and added the spinal dexmedetomidine group for comparison. The lack of effect of IV dexmedetomidine was unexpected. There may have been an effect of dexmedetomidine on the $24 \mathrm{~h}$ analgesic consumption, but we were unable to detect this as we only measured the time to first analgesic.

\section{Conclusion}

We conclude that sensory block after spinal anesthesia with 40 mg chloroprocaine can be prolonged by adding spinal dexmedetomidine without any hemodynamic or neurological side effects. This is associated with a small delay in time to first micturition and hospital discharge after knee arthroscopy in day case surgery. A single dose of IV dexmedetomidine did not prolong sensory block with $40 \mathrm{mg}$ of spinal chloroprocaine.
The number of "low" sensory blocks was higher in the IV DEX group but without clinical consequences. This phenomenon should be further explored by future research.

\section{Data Sharing Statement}

Data are available on request to the corresponding author.

\section{Acknowledgments}

The authors thank Jörgen Bruhn for his critical reading of the manuscript.

\section{Funding}

Funding was departmental.

\section{Disclosure}

The authors report no conflicts of interest in this work.

\section{References}

1. Goldblum E, Atchabahian A. The use of 2-chloroprocaine for spinal anaesthesia. Acta Anaesthesiol Scand. 2013;57:545-552. doi:10.1111/ aas. 12071

2. Breebaart MB, Teune A, Sermeus LA, et al. Intrathecal chloroprocaine vs. lidocaine in day-case surgery: recovery, discharge and effect of pre-hydration on micturition. Acta Anaesthesiol Scand. 2014;58:206-213. doi:10.1111/aas.12247

3. Choi S, Mahon P, Awad IT. Neuraxial anesthesia and bladder dysfunction in the perioperative period: a systematic review. Can J Anaesth. 2012;59:681-703. doi:10.1007/s12630-012-9717-5

4. Elia N, Culebras X, Mazza C, et al. Clonidine as an adjuvant to intrathecal local anesthetics for surgery: systematic review of randomized trials. Reg Anesth Pain Med. 2008;33:159-167.

5. Kamphuis ET, Kuipers PW, van Venrooij GE, et al. The effects of spinal anesthesia with lidocaine and sufentanil on lower urinary tract functions. Anesth Analg. 2008;107:2073-2078. doi:10.1213/ ane.0b013e318187bc0e

6. Naaz S, Bandey J, Ozair E, et al. Optimal dose of intrathecal dexmedetomidine in lower abdominal surgeries in average Indian adult. $J$ Clin Diagn Res. 2016;10:UC09-13.

7. Abdallah FW, Abrishami A, Brull R. The facilitatory effects of intravenous dexmedetomidine on the duration of spinal anesthesia: a systematic review and meta-analysis. Anesth Analg. 2013;117:271278. doi:10.1213/ANE.0b013e318290c566

8. De Jonghe B, Cook D, Appere-de-vecchi C, et al. Using and understanding sedation scoring systems: a systematic review. Intensive Care Med. 2000;26:275-285. doi:10.1007/s001340051150

9. Pavlin DJ, Pavlin EG, Gunn HC, et al. Voiding in patients managed with or without ultrasound monitoring of bladder volume after outpatient surgery. Anesth Analg. 1999;89:90-97. doi:10.1213/ 00000539-199907000-00016

10. Breebaart MB, Vercauteren MP, Hoffmann VL, et al. Urinary bladder scanning after day-case arthroscopy under spinal anaesthesia: comparison between lidocaine, ropivacaine, and levobupivacaine. $\mathrm{Br} \mathrm{J}$ Anaesth. 2003;90:309-313. doi:10.1093/bja/aeg078

11. Mahendru V, Tewari A, Katyal S, et al. A comparison of intrathecal dexmedetomidine, clonidine, and fentanyl as adjuvants to hyperbaric bupivacaine for lower limb surgery: a double blind controlled study. $J$ Anaesthesiol Clin Pharmacol. 2013;29:496-502. doi:10.4103/09709185.119151 
12. Shukla U, Prabhakar T, Malhotra K, et al. Dexmedetomidine versus midazolam as adjuvants to intrathecal bupivacaine: a clinical comparison. J Anaesthesiol Clin Pharmacol. 2016;32:214-219. doi:10.4103/0970-9185.182105

13. Gupta M, Shailaja S, Hegde KS. Comparison of intrathecal dexmedetomidine with buprenorphine as adjuvant to bupivacaine in spinal asnaesthesia. J Clin Diagn Res. 2014;8:114-117.

14. Al-Mustafa MM, Abu-Halaweh SA, Aloweidi AS, et al. Effect of dexmedetomidine added to spinal bupivacaine for urological procedures. Saudi Med J. 2009;30:365-370.

15. Davis BR, Kopacz DJ. Spinal 2-chloroprocaine: the effect of added clonidine. Anesth Analg. 2005;100:559-565. doi:10.1213/01. ANE.0000143381.30409.62

16. Grewal A. Dexmedetomidine: new avenues. J Anaesthesiol Clin Pharmacol. 2011;27:297-302. doi:10.4103/0970-9185.83670

17. Zhang H, Zhou F, Li C, et al. Molecular mechanisms underlying the analgesic property of intrathecal dexmedetomidine and its neurotoxicity evaluation: an in vivo and in vitro experimental study. PLoS One. 2013;8:e55556. doi:10.1371/journal.pone.0055556
18. Nikhila R, Ravi M, Dinesh K. Effect of Intravenous Dexmedetomidine on prolongation of $0,5 \%$ Hyperbaric Bupivacaine. IOSR J Dental Med Sci. 2015;14:58-64.

19. Jung SH, Lee SK, Lim KJ, et al. The effects of single-dose intravenous dexmedetomidine on hyperbaric bupivacaine spinal anesthesia. $J$ Anesth. 2013;27:380-384. doi:10.1007/s00540-012-1541-0

20. Fettes PD, Jansson JR, Wildsmith JA. Failed spinal anaesthesia: mechanisms, management, and prevention. $\mathrm{Br} J$ Anaesth. 2009;102:739-748. doi:10.1093/bja/aep096

21. Mohamed AA, Fares KM, Mohamed SA. Efficacy of intrathecally administered dexmedetomidine versus dexmedetomidine with fentanyl in patients undergoing major abdominal cancer surgery. Pain Physician. 2012;15:339-348. doi:10.36076/ppj.2012/15/339

22. Kaya FN, Yavascaoglu B, Turker G, et al. Intravenous dexmedetomidine, but not midazolam, prolongs bupivacaine spinal anesthesia. Can J Anaesth. 2010;57:39-45. doi:10.1007/s12630-009-9231-6

23. Manassero A, Fanelli A. Prilocaine hydrochloride $2 \%$ hyperbaric solution for intrathecal injection: a clinical review. Local Reg Anesth. 2017;10:15-24. doi:10.2147/LRA.S112756

\section{Publish your work in this journal}

Local and Regional Anesthesia is an international, peer-reviewed, open access journal publishing on the development, pharmacology, delivery and targeting and clinical use of local and regional anesthetics and analgesics. The journal welcomes submitted papers covering original research, basic science, clinical studies, reviews \& evaluations, guidelines, expert opinion and commentary, case reports and extended reports. The manuscript management system is completely online and includes a very quick and fair peer-review system, which is all easy to use. Visit http://www.dovepress.com/testimonials. php to read real quotes from published authors. 